\title{
Intact mAb LC-MS for drug concentration from pre-clinical studies: bioanalytical method performance and in-life samples
}

\author{
John F Kellie*,1(i), Yun W Alelyunas² ${ }^{2}$ Josh Albert' ${ }^{1}$ Nicole A Schneck', Zhuo Chen'1, \\ Caroline J Sychterz ${ }^{1}$, Ian Edwards², Henry Shion², Mark D Wrona² \& Matthew E Szapacs ${ }^{1}$ \\ ${ }^{1}$ Bioanalysis, Immunogenicity \& Biomarkers, GSK, 1250 S. Collegeville Rd., Collegeville, PA 19426, USA \\ ${ }^{2}$ Scientific Operations, Waters Corporation, 34 Maple St, Milford, MA 01757, USA \\ *Author for correspondence: john.x.kellie@gsk.com
}

Background: Antibody biotherapeutic measurement from pharmacokinetic studies has not been traditionally based on intact molecular mass as is the case for small molecules. However, recent advancements in protein capture and mass spectrometer technology have enabled intact mass detection and quantitation for dosed biotherapeutics. A bioanalytical method validation is part of the regulatory requirement for sample analysis to determine drug concentration from in-life study samples. Results/methodology: Here, an intact protein LC-MS assay is subjected to mock bioanalytical method validation, and unknown samples are compared between intact protein LC-MS and established bioanalytical assay formats: Ligandbinding assay and peptide LC-MS/MS. Discussion/conclusion: Results are presented from the intact and traditional bioanalytical method evaluations, where the in-life sample concentrations were comparable across method types with associated data analyses presented. Furthermore, for intact protein LC-MS, modification monitoring and evaluation of data processing parameters is demonstrated.

First draft submitted: 16 June 2020; Accepted for publication: August 2020; Published online: 25 September 2020

Keywords: bioanalytical method validation $\bullet$ biotherapeutics $\bullet$ intact protein mass spectrometry $\bullet$ LC-MS $\bullet$ pharmacokinetics

Biotherapeutic drug quantitation for pharmacokinetic $(\mathrm{PK})$, toxicokinetic $(\mathrm{TK})$ and first time in human studies is critical for drug discovery and development. Historically, ligand-binding assays (LBAs) were the first bioanalytical methods to be implemented for biotherapeutic concentration determination from in-life studies. LBAs may utilize different combinations of generic anti-human IgG, therapeutic target, anti-idiotype and non-neutralizing antiidiotype reagents for capture or detection [1-4]. Over time, MS-based workflows progressed to enable quantitation of protein therapeutics with a digestion-based, surrogate peptide approach [5-8], where a single peptide is used to infer protein concentration and analysis is typically carried out on a triple quadrupole (QQQ) mass spectrometer [9]. For biotherapeutic peptides and small proteins, several examples have demonstrated intact mass quantification on tripleQQQ and high-resolution MS (HRMS) systems [10-13]. Recent advances in HRMS technologies and optimized immunocapture techniques have enabled intact mass detection of large-mass biotherapeutics by LC-MS [14-17].

Intact protein LC-MS assays may offer different advantages and drawbacks compared with LBAs or surrogate peptide LC-MS/MS assays. For example, LBAs give useful information about function, but mass loss (e.g., catabolites or clipping) cannot be detected without developing assays that utilize reagents specific for these catabolic forms $[18,19]$. While surrogate peptide LC-MS/MS can achieve the best sensitivity for an LC-MS assay, the approach monitors only a small portion of the amino acid sequence, and information about the intact molecule and function is lost. Intact protein LC-MS provides a global view, allowing the structural integrity of the molecule to be monitored, including any abundant mass changes. Furthermore, intact protein LC-MS require less assay reagents than both LBAs and enzyme-based peptide LC-MS/MS assays. However, implementation of intact protein LCMS of large proteins for regulated PK, TK and first time in human studies has yet to be demonstrated. Compared with intact protein LC-MS methods, LBAs or surrogate peptide LC-MS/MS methods are usually more sensitive 
and have established data handling and acceptance parameters. Several recommendations on bioanalytical method validations (BMV) for LBAs and surrogate peptide LC-MS/MS have been reported, and years of implementation have enabled streamlined data processing for established formats $[8,20,21]$.

Although intact protein LC-MS assays may need improvement with regards to sensitivity and data processing, the workflow has clear benefits and may help provide a better understanding of biotherapeutic PK. Specially, intact protein molecule PK can be complementary to (rather than a replacement for) standard LBAs and/or can help with LBA troubleshooting [22]. In laboratories equipped for LC-MS in early discovery, intact protein LC-MS may serve as a replacement for digestion-based assays, especially for initial PK studies where low limits of detection or quantitation are not required. Additionally, intact protein LC-MS methods should require less sample preparation time and enzyme cost compared with a surrogate peptide LC-MS/MS assay.

Here, the aim of this study is to evaluate many of the experiments compromising a traditional BMV and help provide insight toward the capabilities of an intact protein LC-MS approach for absolute quantitation for support of a PK/TK study end point. Precision and accuracy runs $(\mathrm{n}=3)$, processed sample stability $(36 \mathrm{~h})$, room temperature stability $(24 \mathrm{~h}$ ), long-term storage stability ( 408 days), freeze-thaw stability (five cycles from $-80^{\circ} \mathrm{C}$ ) are presented. Sample run results from intact protein LC-MS, surrogate peptide LC-MS/MS (from trypsin digestion) and LBA are also highlighted. For quantitation, selected data from alternative approaches are presented for simple comparison. Glycoform abundance monitoring by intact mass is also shown from in-life study samples as an example of utility of intact protein MS to monitor mass variants from study samples. Data presented herein indicate that intact protein LC-MS can be a viable bioanalytical assay, demonstrating similar assay performance as LBAs or surrogate peptide LC-MS/MS assays. In addition, data processing strategies evaluated may lead to similar assay performance but also may need case-by-case evaluation.

\section{Materials \& methods}

Chemicals \& reagents

Biotherapeutic GSKmAb and anti-GSKmAb antibodies were generated in-house. Capture antibody for intact and peptide LC-MS was biotinylated goat anti-human IgG, monkey adsorbed (Southern Biotech, AL, USA). Capture antibody for the LBA was an anti-GSKmAb antibody, and the detection antibody was HRP-labeled mouse antihuman $\operatorname{IgG}_{1}, \mathrm{~F}_{\mathrm{C}}$ specific (Molecular Probes, OR, USA). The GSKmAb LC-MS assays used Pierce (Rockford, IL, USA) streptavidin high binding capacity coated 96-well Plate. Blocking and assay buffer for each LC-MS assay was Superblock ${ }^{\circledR}$ T20 phosphate-buffered saline blocking buffer (Thermo Fisher Scientific, MA, USA). Tween 20, $20 \times$ PBS buffer, trifluoracetic acid (TFA), acetonitrile, $0.1 \%$ formic acid in water, isopropyl alcohol, acetic acid, sodium bicarbonate and trypsin were purchased from Thermo Fisher Scientific. Gibco PBS solution (pH 7.4) was purchased from Life Technologies (CA, USA). Glycinator (EndoS2) was purchased from Genovis (MA, USA). The LC-MS assays used Waters ACQUITY UPLC systems. The intact LC-MS assay used a Waters Xevo G2-XS Q-TOF MS. The peptide LC-MS assay used a Waters Xevo TQ-S tandem MS. The GSKmAb LBA assay used a Nunc Maxisorp clear 96-well plate. BupHTM $50 \mathrm{mM}$ sodium carbonate-bicarbonate buffer $\mathrm{pH}$ 9.4, Tris Buffered Saline (TBS), Tween 20 Tablets, bovine serum albumin (BSA) 1-Step TMB-ELISA, TMB Substrate Stop Solution were purchased from Thermo Fisher Scientific. The LBA plate reader was the PerkinElmer 2030 Manager v4.0.

\section{In-life study details \& sample collection}

Cynomolgus monkeys were dosed at $10 \mathrm{mg} / \mathrm{kg}$ GSKmAb and serum samples were collected at the following nominal times: $0.25,0.5,1,2,3,4,24,48$ and $168 \mathrm{~h}$ post dose. All samples were stored at $-20^{\circ} \mathrm{C}$ or below until analyzed. All studies were conducted in accordance with the GSK Policy on the Care, Welfare and Treatment of Laboratory Animals and were reviewed by the Institutional Animal Care and Use Committee either at GSK or by the ethical review process at the institution where the work was performed. All animal studies were ethically reviewed and carried out in accordance with Animals (Scientific Procedures) Act 1986 and the GSK Policy on the Care, Welfare and Treatment of Animals.

\section{Solution preparations for LC-MS}

Antibody solutions were generated by diluting capture antibody into Superblock buffer appropriately. In addition, $10 \mathrm{mM}$ sodium phosphate, $150 \mathrm{mM} \mathrm{NaCl}, 0.1 \%$ tween 20 , $\mathrm{pH} 7.5$ wash buffer was prepared by adding 3.81 of ultra-pure water, $200 \mathrm{ml}$ of $20 \times$ PBS Buffer, $\mathrm{pH} 7.5$ and $4 \mathrm{ml}$ of tween 20 to a 41 container and mixing thoroughly. Superblock buffer was used as supplied for assay buffers. Gibco PBS solution ( $\mathrm{pH} 7.4)$ was used as supplied for 
detergent-free washing. For reduction, $50 \mathrm{mM}$ DTT in water was prepared by adding $50 \mu \mathrm{l} 1 \mathrm{M} \mathrm{DTT}$ to $950 \mu \mathrm{l}$ ultra-pure water. Trypsin was prepared at $1 \mathrm{mg} / \mathrm{ml}$ in $50 \mathrm{mM}$ acetic acid and further diluted to $10 \mu \mathrm{g} / \mathrm{ml}$ trypsin in $80 / 20$ (v/v), $100 \mathrm{mM}$ sodium bicarbonate, $\mathrm{pH}$ 8.5/ACN (final digestion buffer). Study samples were diluted 201-fold into assay buffer for the peptide LC-MS/MS analysis and 50-fold for the intact LC-MS analysis.

\section{Solution preparations for LBA}

For coating buffer, $50 \mathrm{mM}$ sodium carbonate-bicarbonate buffer $\mathrm{pH} 9.4$ was prepared by dissolving 1 pouch BupHTM in 2.01 with deionized water. Capture antibody solution was prepared by diluting antibody stock solution to $4 \mathrm{mg} / \mathrm{ml}$ in coating buffer. Assay buffer was made by dissolving two Tris Buffered Saline (TBS) with Tween 20 tablets in $1000 \mathrm{ml}$ of water and adding $1.0 \mathrm{~g}$ BSA. Study samples were diluted 200-fold in assay buffer for analysis.

\section{Sample preparation, immunocapture \& elution procedure: LC-MS}

First, $100 \mu \mathrm{l}$ of capture antibody solution $(15 \mu \mathrm{g} / \mathrm{ml}$ capture antibody in assay buffer) was added to each well. The plate was incubated for $60 \mathrm{~min}$ at $37^{\circ} \mathrm{C}$ while shaking. Following incubation, a BioTek ELx 405 Plate Washer (VT, USA) was employed to remove the capture solution and wash the plate five-times with wash buffer. Next, $2 \mu \mathrm{l}$ of known or unknown sample diluted to $100 \mu \mathrm{l}$ in assay buffer was added to each well. Samples were diluted into assay range with blank serum and processed alongside dilution process controls when required. Samples were incubated for $90 \mathrm{~min}$ at $37^{\circ} \mathrm{C}$ while shaking. For sample preparation involving deglycosylation, $3 \mu \mathrm{l}$ of EndoS2 enzyme was added to each $100 \mu \mathrm{l}$ of sample/assay buffer mixture. After sample incubation was complete, the residual plasma/buffer sample was removed, and the plate was washed five-times with wash buffer using a BioTek Plate Washer. Afterward, the plate was washed with water five-times. For intact mass analysis, $100 \mu \mathrm{l}$ of $1 \%$ acetic acid in water was added to each well and gently mixed for $30 \mathrm{~s}$ prior to analysis by LC-MS. For peptide LC-MS/MS, $100 \mu \mathrm{l}$ final digestion buffer with $1 \mu \mathrm{g} / \mathrm{ml}$ internal standard was added to each well and incubated for approximately $18 \mathrm{~h}$. After digestion, $20 \mu \mathrm{l}$ of $10 \%$ formic acid was added prior to analysis by LC-MS.

\section{Sample preparation, \& immunoassay: LBA}

For capture, $100 \mu \mathrm{l}$ antibody solution was added to each well, and incubated for $24 \mathrm{~h}( \pm 12 \mathrm{~h})$ at $4^{\circ} \mathrm{C}$. The plate was then washed five-times with $300 \mu \mathrm{l}$ wash buffer using a plate washer. Afterward, $200 \mu$ l blocking buffer was added to each well and incubated for approximately $1 \mathrm{~h}$ at $37^{\circ} \mathrm{C}$, followed by another $5 \times$ wash. Then, $100 \mu \mathrm{l}$ per well of standards, quality controls (QCs) and/or samples was added and incubated with constant shaking for $2 \mathrm{~h}$ at $37^{\circ} \mathrm{C}$, followed by washing five-times. A total of $100 \mu \mathrm{l}$ of reporter tag solution was added to each well and incubated with constant shaking for $1 \mathrm{~h}$ at $37^{\circ} \mathrm{C}$. The plate was washed five-times and $100 \mu \mathrm{l}$ development substrate solution was added to each well and incubated at room temperature with shaking for $30 \mathrm{~min}$. Finally, $100 \mu \mathrm{l}$ stop solution was added to each well and the absorbance was read at $450 \mathrm{~nm}$ using plate reader.

\section{LC-MS conditions: intact LC-MS}

For intact LC-MS analyses, $25 \mu \mathrm{l}$ of each sample was injected. LC separation was carried out using a Waters ACQUITY UPLC I-Class system including a sample manager with flow-through needle. The LC column used was a Thermo Scientific, MabPac RP $(1 \mathrm{~mm} \times 50 \mathrm{~mm}, 4 \mu \mathrm{m}, 1500 \AA)$ with a $0.25 \mathrm{ml} / \mathrm{min}$ flow rate. LC buffer A consisted of $0.1 \%$ formic acid and $0.02 \%$ TFA in water, and LC buffer B consisted of acetonitrile. The sample was loaded directly on the column by the following LC gradient with a total run time of $5 \mathrm{~min}$ at $80^{\circ} \mathrm{C}$. The gradient was as follows: hold $80 \%$ A for 2 min, flow to $20 \%$ A in 15 s, hold $20 \%$ A for $1.25 \mathrm{~min}$, flow to $80 \%$ A in $30 \mathrm{~s}$ and hold $80 \% \mathrm{~A}$ for $1 \mathrm{~min}$.

The MS instrument used for detection was a Waters G2-XS Q-TOF operating in TOF MS positive ESI mode with a Z-Spray electrospray source. The following instrument settings were used: source temperature at $150^{\circ} \mathrm{C}$, desolvation temperature at $500^{\circ} \mathrm{C}$, capillary voltage at $2.5 \mathrm{kV}$, sampling cone at $150 \mathrm{~V}$, source offset at $150 \mathrm{~V}$, cone gas at $0 \mathrm{l} / \mathrm{h}$, desolvation gas at $700 \mathrm{l} / \mathrm{h}$, analyzer mode set to sensitivity, dynamic range set to normal, sensitivity set to normal, detection range from 2500 to $4000 \mathrm{~m} / z$, data type set to continuum, scan time at $0.4 \mathrm{~s}$ and trap and transfer collision energies were off. 


\section{LC-MS conditions: surrogate peptide LC-MS/MS}

For surrogate peptide LC-MS/MS analysis, $10 \mu \mathrm{l}$ of each sample was injected. The LC separation was carried out using a Waters ACQUITY UPLC I-Class system including a sample manager with Flow Through Needle. The LC column used was a Waters ACQUITY UPLC Peptide BEH C18 $(300 \AA$, $1.7 \mu \mathrm{m}, 2.1 \times 50 \mathrm{~mm})$ with a $0.8 \mathrm{ml} / \mathrm{min}$ flow rate. LC buffer A consisted of $0.1 \%$ formic acid in water, and LC buffer B was acetonitrile. The sample was loaded directly onto the column by the following LC gradient with a total run time of 4 min at $80^{\circ} \mathrm{C}$. Flow for loading was at $80 \%$ buffer A to $70 \%$ buffer A over $2.5 \mathrm{~min}$; followed by flow to $20 \%$ buffer A over $0.5 \mathrm{~min}$; flow to $80 \%$ buffer A over $0.5 \mathrm{~min}$. The MS used for detection was a Waters TQ-S operating in MRM mode with a Z-Spray electrospray source. The following instrument settings were used: source temperature at $150^{\circ} \mathrm{C}$, desolvation temperature $600^{\circ} \mathrm{C}$, capillary voltage at $+2.5 \mathrm{kV}$, sampling cone at $30 \mathrm{~V}$, source offset at $60 \mathrm{~V}$, cone gas at $150 \mathrm{l} / \mathrm{h}$, desolvation gas at $800 \mathrm{l} / \mathrm{h}$. A GSKmAb peptide was selected from the heavy chain (unique to GSKmAb), with as heavy-labeled internal standard utilized.

\section{Quantitation}

For LBA, the standard curve was fitted to a $1 / \mathrm{x}^{2}$ weighted five parameter logistic algorithm using absorbance values. For surrogate peptide LC-MS/MS, the standard curve was fitted using $1 / \mathrm{x}^{2}$ weighted linear regression using peak area ratios determined using TargetLynx. For intact LC-MS, the standard curve was fitted using $1 / \mathrm{x}^{2}$ weighted linear regression using peak area from either observed extracted ion chromatogram (XIC) based quantitation or deconvolution. UNIFI software (Build 1.9.4.053) was used for intact LC-MS data processing. For observed XIC based quantitation, 'Quantify Assay TOF 2D Chromatographic' analysis method was used. The quantitation was assessed using mass tolerance windows of $0.5,1.0,1.5$ or $2.0 \mathrm{Da}$. The number of XIC inclusions in each charge state was also assessed from single XIC, sum of three XIC, sum of six XIC or sum of 20 XIC. Masses used for each XIC variation are as follows: single XIC, $m / z=3431.001$; sum of three XIC, $m / z=3598.201$, 3688.981, 3783.951; sum of six XIC, $m / z=3430.87,3612.60$, 3598.21, 3686.98, 3783.95, 3882.33; sum of 20 XIC, $m / z=2635.0,2683.0,2732.0,2784.0,2837.0,2893.0,3011.0,3074.0,3139.0,3207.0$, 3279.0, 3353.0, $3431.0,3513.0,3599.0,3689.0,3783.0,3883.0,3988.0$ and 2951.0. In peak integration, a 'mean' smoothing algorithm with half width of fifth and iteration of three were used. Automatic peak width and automatic peak detection threshold was used. There were no baseline nor peak manual adjustment for all samples processed. For quantitation through deconvolution, 'Intact Protein (MS-RT Window Based)' analysis method was used. MaxEnt1 deconvolution parameters used were as follows: start peak width was 1.1 Da; end peak width was 1.2 Da; number of iterations was eight. Expected $m / z$ in component table was 147,493.5. Post data process, the MS response from deconvoluted intact workflow was exported to Excel for further assessment of linearity and reproducibility.

\section{Results}

\section{Intact protein quantitation workflow \& example data}

In-life sample analysis for PK concentration determination for a GSKmAb was performed by different bioanalytical methods over the drug's discovery and early development stages. Both LBA and LC-MS analysis was utilized, and assay schematics are shown in Figure 1. For each assay, the GSKmAb was immunopurified from cynomolgus monkey serum using a streptavidin 96-well plate coated with capture antibody. The LC-MS assays used anti-human IgG capture, and the purified GSKmAb was either released under acidic conditions (intact protein approach) or digested with trypsin on-plate (surrogate peptide approach), followed by LC-MS analysis. For the intact LC-MS, the assay range was $5-50 \mu \mathrm{g} / \mathrm{ml}$. The surrogate peptide LC-MS/MS assay utilized a single, unique surrogate peptide from the heavy chain of the GSKmAb to infer whole-antibody concentration. For surrogate peptide LC-MS/MS, the assay range was $5-100 \mu \mathrm{g} / \mathrm{ml}$. The LBA used an anti-idiotype capture with labeled anti-human IgG detection, with a range of $1-100 \mu \mathrm{g} / \mathrm{ml}$. The assay ranges were designed to match the expected in-life concentrations of the study samples at late sampling time points.

Example data for the intact LC-MS workflow are shown in Figure 2. In Figure 2A, the mass spectra from approximately $2500-4000 \mathrm{~m} / z$ were combined for the LC elution peak from a $40 \mu \mathrm{g} / \mathrm{ml}$ QC sample and shown with a charge state distribution from $58+$ to $38+$. The deconvoluted intact mass derived from the mass spectrum is shown in Figure 2B. The GSKmAb with G0F/G0F and G0F/G1F peaks are detected in the deconvoluted mass spectrum. In Figure 2C, XICs are overlaid for 20 charge states in the acquired $m / z$ range, where charge states on the edge of the expected Gaussian distribution have lower intensities than the peak charge states.

An example of the quantitative data from a standard curve is shown in Figure 3. In Figure 3A, left panels show 


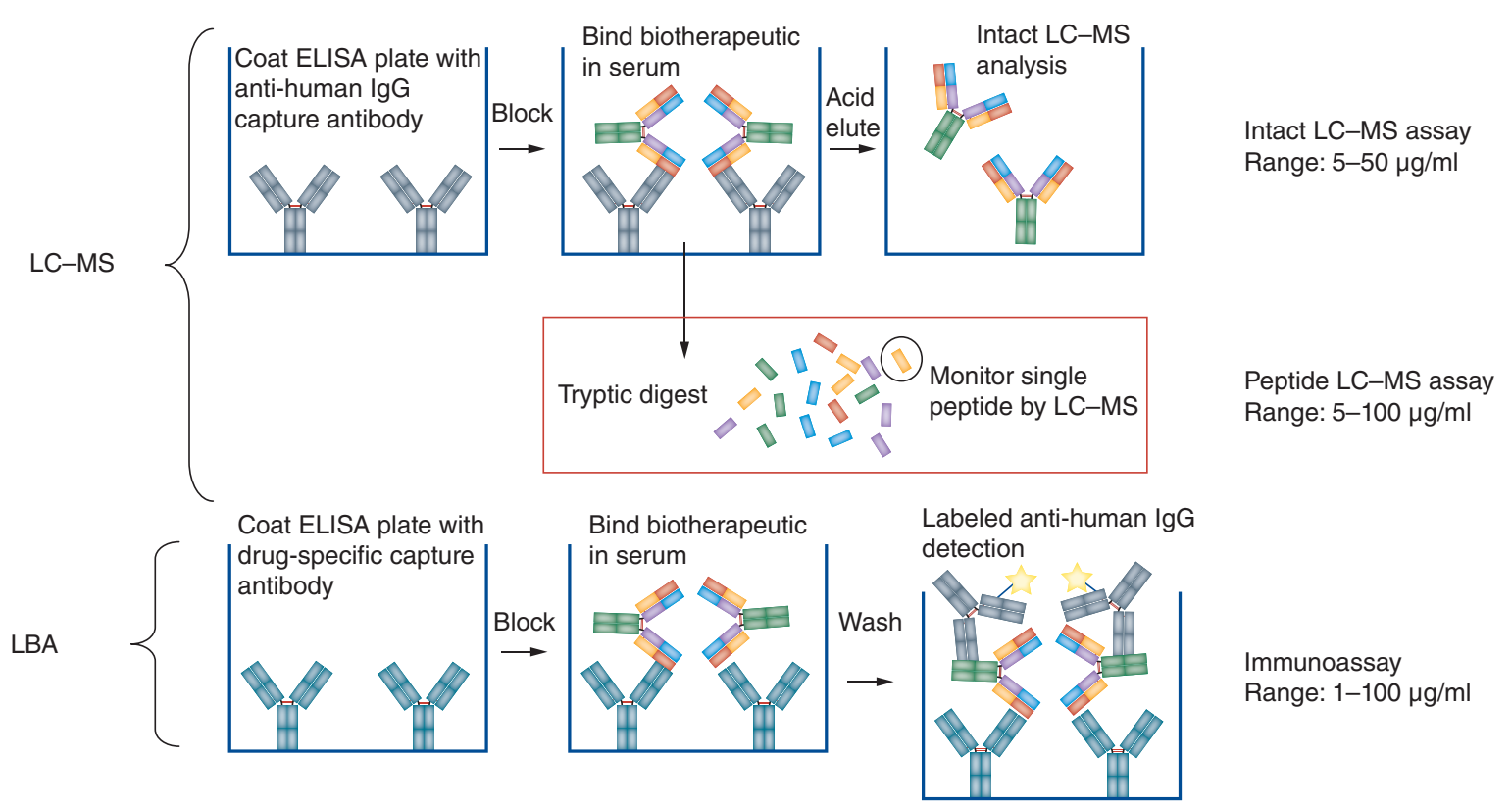

Figure 1. Depictions of assays used for analysis of GSKmAb. Two LC-MS assays and one ligand-binding assay were utilized. The LC-MS assays used the same capture step, with either acid elution for intact mass or digestion for surrogate-peptide LC-MS/MS. For the ligand-binding assay, a drug-specific anti-idiotype antibody was the capture reagent, and a similar reagent (generic anti-human IgG) was used as the capture reagent in the LC-MS assays.

\begin{tabular}{|c|c|c|c|c|c|c|c|c|c|c|c|c|}
\hline \multicolumn{2}{|c|}{ Concentration $(\mu \mathrm{g} / \mathrm{ml})$} & \multicolumn{2}{|c|}{ Day 1} & \multicolumn{3}{|c|}{ Day 2} & \multicolumn{3}{|c|}{ Day 3} & \multicolumn{3}{|c|}{ Total } \\
\hline & $\mathrm{n}$ & $\begin{array}{l}\text { Accuracy } \\
\text { (\% bias) }\end{array}$ & $\begin{array}{l}\text { Precision } \\
\text { (\% CV) }\end{array}$ & $n$ & $\begin{array}{l}\text { Accuracy } \\
\text { (\% bias) }\end{array}$ & $\begin{array}{l}\text { Precision } \\
(\% \mathrm{CV})\end{array}$ & $n$ & $\begin{array}{l}\text { Accuracy } \\
\text { (\% bias) }\end{array}$ & $\begin{array}{l}\text { Precision } \\
\text { (\% CV) }\end{array}$ & $n$ & $\begin{array}{l}\text { Accuracy } \\
\text { (\% bias) }\end{array}$ & $\begin{array}{l}\text { Precision } \\
(\% \mathrm{CV})\end{array}$ \\
\hline 5 & 6 & 1.7 & 7.8 & 6 & 0.4 & 9.1 & 6 & 2.1 & 13.2 & 18 & 1.4 & 10 \\
\hline 15 & 6 & 7.4 & 3.7 & 6 & 18.8 & 2.2 & 6 & 8.3 & 6.9 & 18 & 11.5 & 4.3 \\
\hline 50 & 6 & -11.9 & 6.8 & 6 & -12.3 & 4.7 & 6 & -17 & 3.7 & 18 & -13.7 & 5.1 \\
\hline
\end{tabular}

the XICs from a single charge state. For the right panels, a combined mass spectrum from the LC peak elution window is shown. Results for blank, unspiked serum are shown for demonstration at top. Samples are shown from low to high concentrations (from top to bottom). The sum of areas under the curve for each extracted charge state for each spiked reference standard sample was used to generate a standard curve from 5 to $50 \mu \mathrm{g} / \mathrm{ml}$ (in serum) for QC calculations and unknown sample determination, shown in Figure 3B.

\section{Mock BMV for intact MS analysis}

Several experiments were performed for the intact LC-MS assay to mirror those performed for a typical BMV. The acceptance criteria of 20\% accuracy overall and 25\% accuracy at the LLOQ recommended for hybrid LC-MS/MS of biotherapeutics were employed [23]. The prepared calibration concentration range consisted of seven standards from 5 to $50 \mu \mathrm{g} / \mathrm{ml}$ and no internal standard was used. The calibration was fitted with $1 / \mathrm{x}^{2}$ linear regression, where $75 \%$ of standard curve points must fall within the $\pm 20 / 25 \%$ criteria [23].

Method precision and accuracy were determined for five QC samples at concentrations of 5, 15, 25, 40 and $50 \mu \mathrm{g} / \mathrm{ml}$ spiked into serum in six replicates and measured in three runs on separate days (Table 1). For each QC sample concentration, a total of 18 measurements were performed. Data are presented in aggregate for interday and intraday precision (\% CV) and bias (\% accuracy). All accuracy and precision were within the 20/25\% acceptance criteria for a BMV. Precision values were within 10\% with the exception of the LOQ on Day 2. Day 2 also had the 

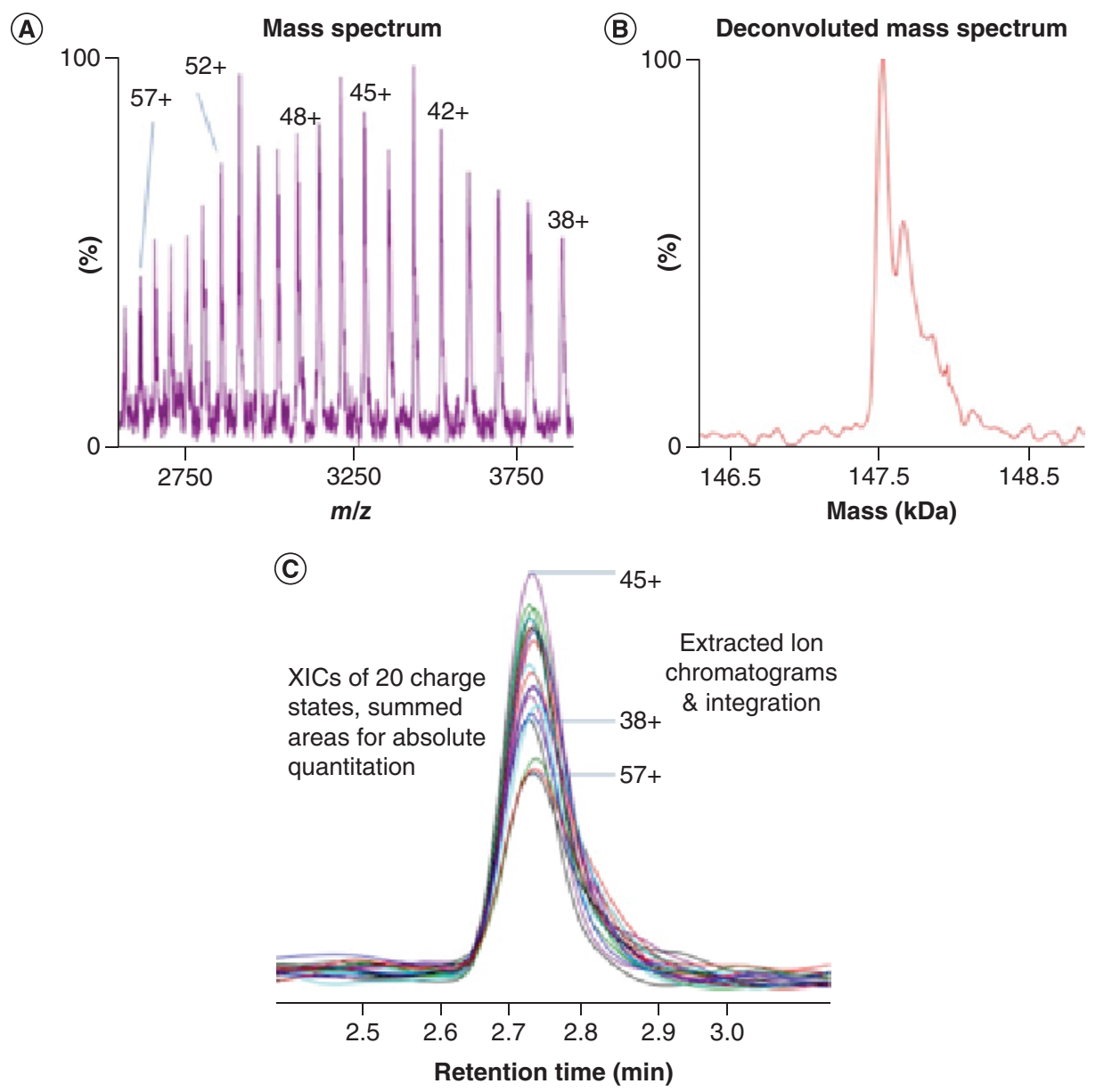

Figure 2. Data from the intact LC-MS assay are shown. In (A), a wide-range mass spectrum is shown with selected charge states labeled. The mass spectrum in (A) was deconvoluted to mass in (B), where the mass for the intact antibody is shown at approximately $147.5 \mathrm{kDa}$. The smoothed extracted ion chromatograms from each of the 23 charge states from 2500 to $4000 \mathrm{~m} / \mathrm{z}$ are shown in (C). Absolute drug quantitation is performed at the $\mathrm{m} / \mathrm{z}$ level by use of summed AUCs from extracted ion chromatograms from each charge state.

XIC: Extracted ion chromatogram.

Table 2. Summary of the stability results for the quality control samples.

\begin{tabular}{|c|c|c|c|c|c|c|c|c|c|}
\hline \multirow[t]{2}{*}{ Stability conditions } & \multirow{2}{*}{$\begin{array}{l}\text { Storage } \\
\text { temperature } \\
\text { (approximate) }\end{array}$} & \multirow[t]{2}{*}{ Duration } & \multirow[t]{2}{*}{$\mathrm{n}$} & \multicolumn{2}{|c|}{$\mathrm{QC} 15 \mu \mathrm{g} / \mathrm{ml}$} & \multicolumn{2}{|c|}{$\mathrm{QC} 25 \mu \mathrm{g} / \mathrm{ml}$} & \multicolumn{2}{|c|}{$\mathrm{QC} 40 \mu \mathrm{g} / \mathrm{ml}$} \\
\hline & & & & $\begin{array}{l}\text { Accuracy } \\
\text { (\% bias) }\end{array}$ & $\begin{array}{l}\text { Precision } \\
\text { (\% CV) }\end{array}$ & $\begin{array}{l}\text { Accuracy } \\
\text { (\% bias) }\end{array}$ & $\begin{array}{l}\text { Precision } \\
\text { (\% CV) }\end{array}$ & $\begin{array}{l}\text { Accuracy } \\
\text { (\% bias) }\end{array}$ & $\begin{array}{l}\text { Precision } \\
\text { (\% CV) }\end{array}$ \\
\hline $\begin{array}{l}\text { Post process } \\
\text { re-injection }\end{array}$ & $4^{\circ} \mathrm{C}$ & $36 \mathrm{~h}$ & 6 & 12.1 & 7.2 & 13.0 & 4.4 & 6.7 & 2.5 \\
\hline Room temp. & $20^{\circ} \mathrm{C}$ & $24 \mathrm{~h}$ & 6 & 10.5 & 3.4 & 9.0 & 3.9 & 12.8 & 2.7 \\
\hline Freeze-thaw & $-80^{\circ} \mathrm{C}$ & 5 cycles & 6 & 11.0 & 2.7 & 5.3 & 4.3 & -6.8 & 5.3 \\
\hline Long term & $-80^{\circ} \mathrm{C}$ & 408 days & 6 & 10.3 & 6.6 & 1.8 & 3.9 & 10.0 & 1.8 \\
\hline
\end{tabular}

widest interday accuracy ranges, with values ranging from 18.8 to $-012.3 \%$ for QC samples at 15 and $50 \mu \mathrm{g} / \mathrm{ml}$, respectively.

In addition to precision and accuracy runs, several stability runs were performed which are often included in BMVs. Room temperature stability, freeze-thaw stability, long-term storage stability and processed sample stability were tested. The results are listed in Table 2 with aggregate statistics for all QCs at low, middle and high concentrations shown. For post process re-injection, samples were re-analyzed $36 \mathrm{~h}$ after the start of the first 
(A)
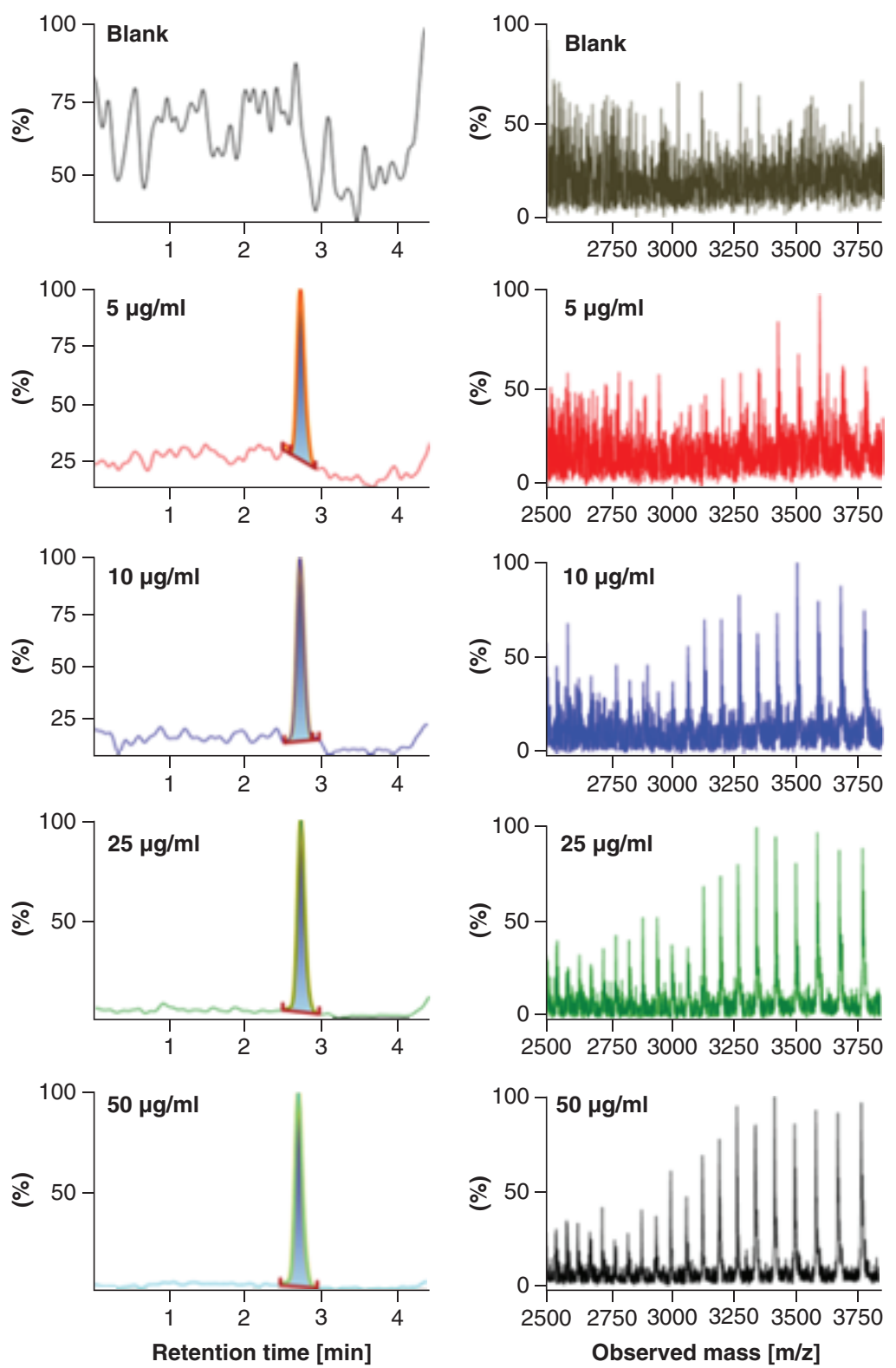

(B)

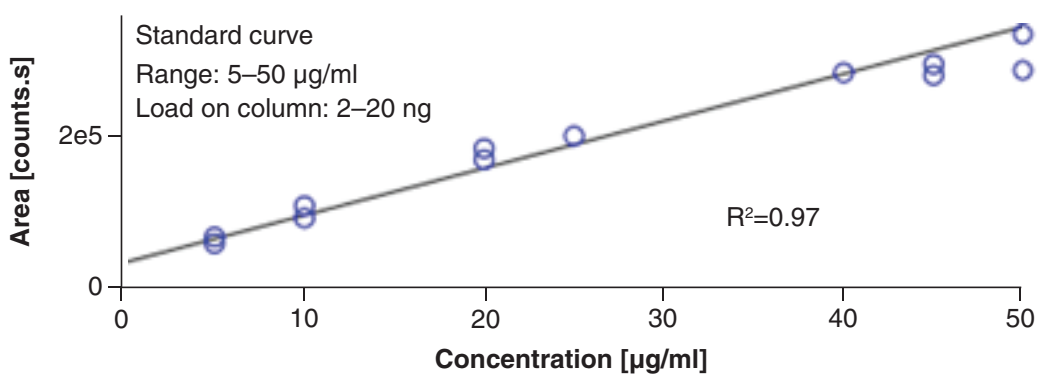

Figure 3. Example chromatograms and spectra from the blank, $5 \mu \mathrm{g} / \mathrm{ml}$ (lower limit of quantitation), $10 \mu \mathrm{g} / \mathrm{ml}$, $25 \mu \mathrm{g} / \mathrm{ml}$ and $50 \mu \mathrm{g} / \mathrm{ml}$ (higher limit of quantitation). (A) Each chromatogram displayed is from a single charge state ( $m / z$ 3431, 43+ charge state). A summed mass spectrum over the LC elution peak for each sample is shown to the left of the respective chromatogram. An example standard curve for fitting of a known quality control and unknown samples is shown at bottom. (B) The intact LC-MS assay range was $5-50 \mu \mathrm{g} / \mathrm{ml}$ using $2 \mu \mathrm{l}$ monkey serum, corresponding to $2-20 \mathrm{ng}$ on column for LC-MS analysis after assay processing. 
Table 3. Calculated percent differences for mean ( $n=3$ animals) sample concentrations between intact LC-MS, peptide LC-MS/MS and the ligand-binding assay.

\begin{tabular}{|c|c|c|}
\hline \multirow[t]{2}{*}{ Time (h) } & \multicolumn{2}{|c|}{ Differences (\%) for mean sample concentrations } \\
\hline & Intact vs LBA & Intact vs peptide \\
\hline 0.25 & -12 & 1.5 \\
\hline 0.50 & -1.1 & 6.1 \\
\hline 0.75 & -15.6 & 37.8 \\
\hline 1 & 4.6 & 1.8 \\
\hline 2 & 6.7 & -12.3 \\
\hline 3 & 0.8 & -20.6 \\
\hline 4 & 0.2 & 0.9 \\
\hline 24 & 2.8 & -13.6 \\
\hline 48 & 5.5 & -24.2 \\
\hline
\end{tabular}

analytical run. For freeze-thaw, samples were brought to room temperature and then re-frozen at $-80^{\circ} \mathrm{C}$ for a total of five cycles. QC samples prepared alongside the original study samples were held at $-80^{\circ} \mathrm{C}$ for a total of 408 days before analysis by intact protein LC-MS. All stability samples met the $\pm 20 / 25 \%$ criteria.

For bioanalytical methods, carry-over is often assessed after the higher limit of quantitation (HLOQ) to determine the possible impact (e.g., over-estimation) for unknown samples. Sample concentration can decrease significantly in a subsequent sampling time point during the course of an in-life study, and testing for presence of carryover can ensure high-concentration samples do not impact calculated concentration values for low-concentration samples [24]. Similarly, the S/N of the blank sample compared with the LLOQ can be assessed. Figure 4 shows mass spectra of an HLOQ $(50 \mu \mathrm{g} / \mathrm{ml})$, LLOQ $(5 \mu \mathrm{g} / \mathrm{ml})$ and a serum blank injection following HLOQ. Panel A shows the full mass range and Panel B shows a zoomed-in mass range. Spectra from HLOQ and blank injections indicate a carry-over of less than 3\% based on S/N in the HLOQ injection and the noise level in the blank, with no protein mass detected in the blank injection. The peak area of serum blank after HLOQ injection is also less than $20 \%$ of LLOQ response, indicating the minimal carry over.

\section{In vivo quantitation of GSKmAb in cynomolgus serum}

PK analysis for Cynomolgus serum samples utilized intact protein LC-MS, surrogate peptide LC-MS/MS and LBA quantitation. For all three methods, the GSKmAb was immunopurified from serum. After immunocapture, the samples were treated according to specific requirements of the method. The intact MS method provided the most direct means of sample preparation, as the mAb released from the capturing antibody was injected directly into the LC-MS. Both LBA and peptide LC-MS/MS assays required additional sample preparation steps after immunocapture.

The in vivo sample set represents a post dose time course from $15 \mathrm{~min}$ to $168 \mathrm{~h}$ of sample collection. Results in the form of concentration-time plots for individual animals are shown in Figure 5, with the mean of the three subjects (to $48 \mathrm{~h}$ ) shown in Figure 5 at bottom right and in Table 3. From the concentration time plots, similar sample concentrations making up the PK profiles were observed. Table 3 quantifies the difference in mean sample concentrations between the assays, with the surrogate peptide LC-MS/MS and LBA compared with the intact LC-MS assay. The values obtained from intact LC-MS and LBA agreed within $\pm 20 \%$. Concentration data for subjects A and B were not quantifiable for some late time point samples, and not captured in the plot.

To support PK and TK study end points, the exposure of the drug to the body of the animal or human is required. Exposure is calculated from the concentration-time curves by performing an integration and determining the AUC. The AUC values for each animal and the average of all animals were calculated to the last quantifiable time point $\left(\mathrm{AUC}_{\text {last }}\right)$ in Supplementary Table 1, and AUC values measured from individual subjects by different assays were within $15 \%$ of the mean for all three assay formats.

\section{Modified mAb identification \& relative abundance monitoring}

GSKmAb contains a traditional $\mathrm{IgG}_{1} \mathrm{~N}$-glycosylation profile. The two most abundant glycoforms were detected as G0F/G0F and G0F/G1F at the intact mass level in the assay, seen in the deconvoluted intact mass spectrum in Figure 2B and examined in Supplementary Figure 1. In Supplementary Figure 1A, zoomed-in mass spectra for 

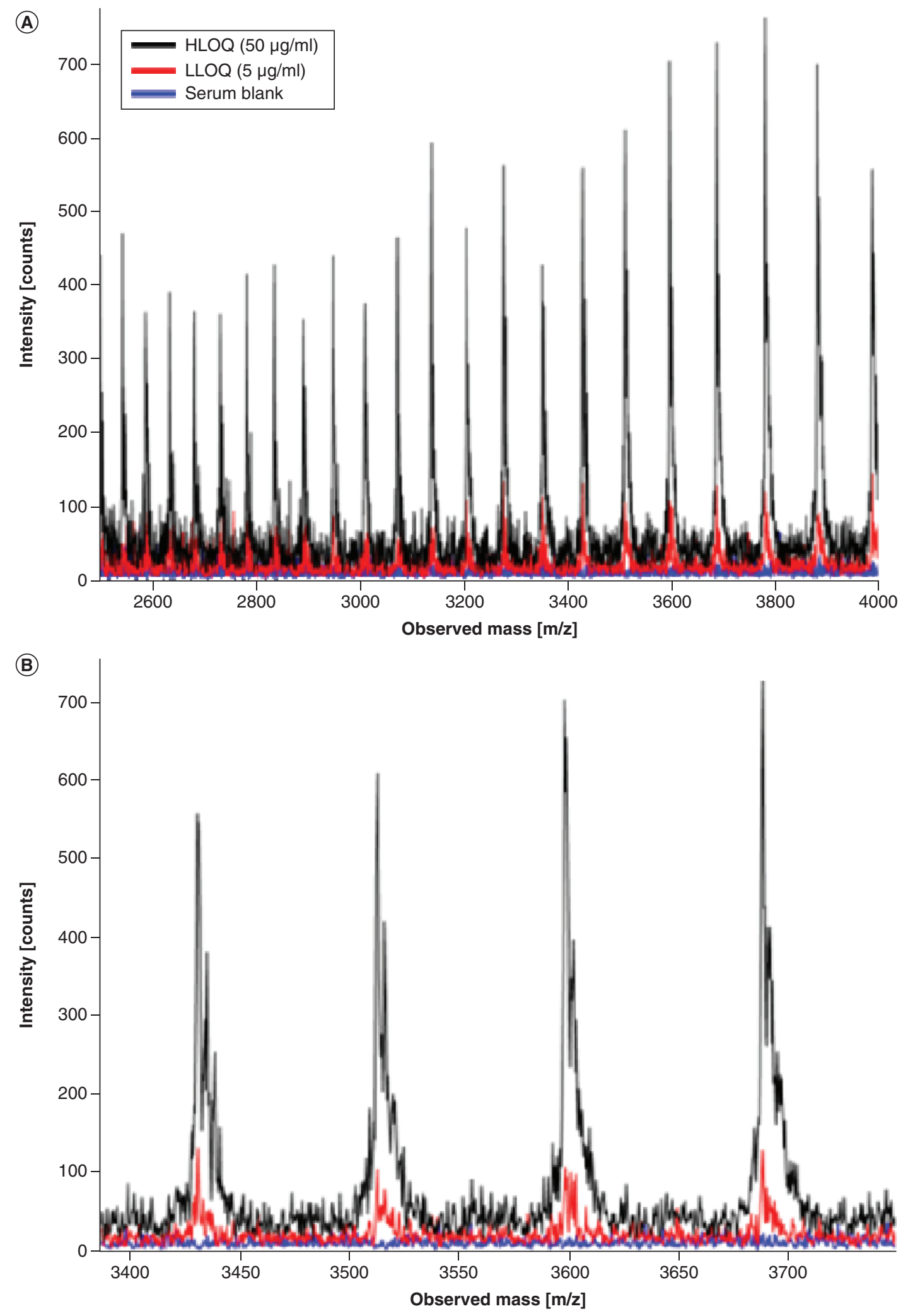

Figure 4. Example intact protein LC-MS data from higher limit of quantitation, LLOQ and blank serum injection (after higher limit of quantitation). (A) Shows mass spectra from 2500 to $4000 \mathrm{~m} / \mathrm{z}$. A zoomed-in (B) shows four charge states to further demonstrate that no drug is detected in the blank sample. The mass spectra can be used to help determine carry over and S/N at the LLOQ.

HLOQ: Higher limit of quantitation; LLOQ: Lower limit of quantitation. 


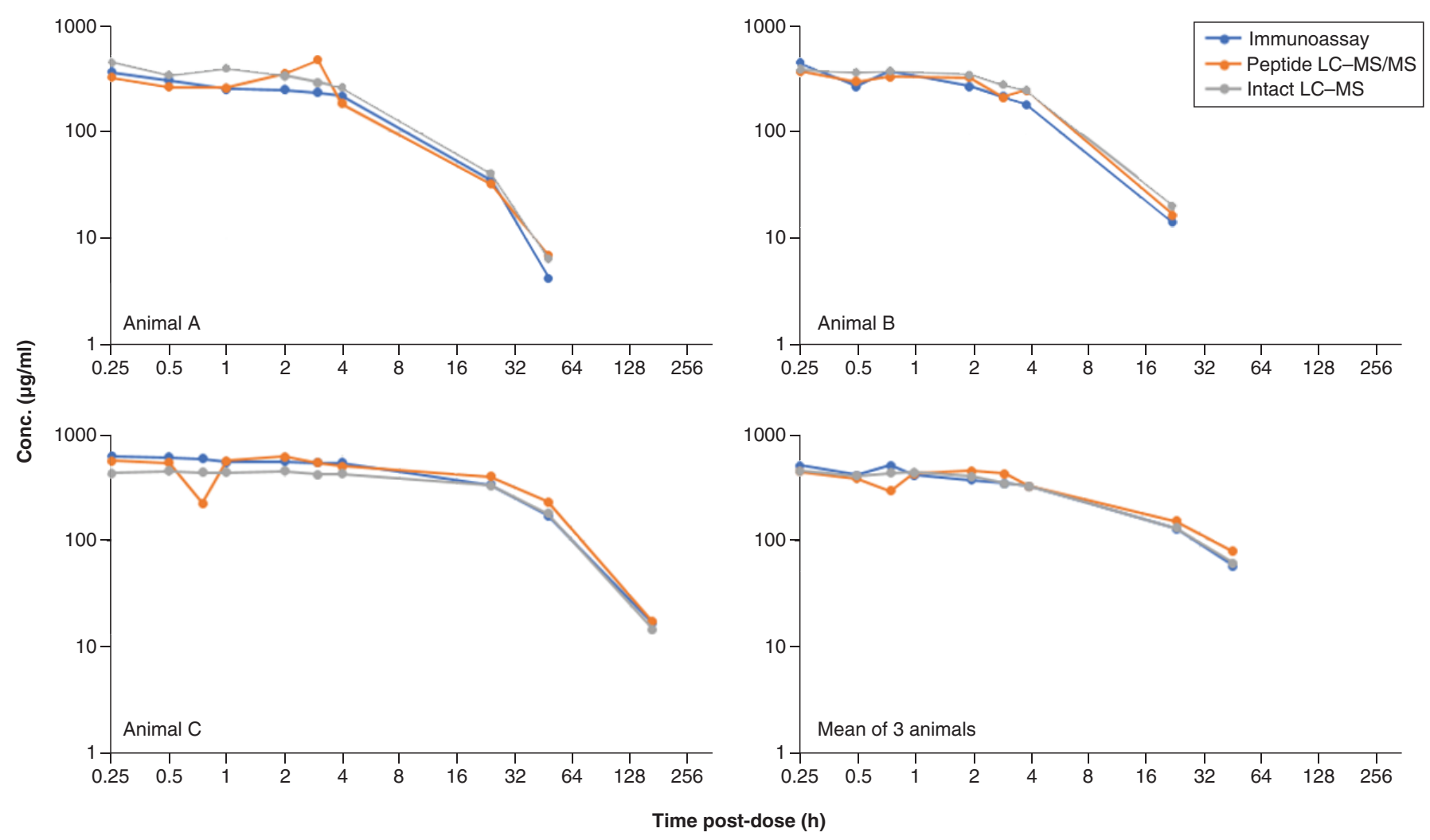

Figure 5. Concentration-time curves from immunoassay (ligand-binding assay) peptide LC-MS/MS and intact LC-MS assays. Three monkeys were dosed GSKmAb at $10 \mathrm{mg} / \mathrm{kg}$, and drug concentration in serum was monitored as a function of time post dose, with the last time point at $168 \mathrm{~h}$. For animal (A), drug was not detected after $48 \mathrm{~h}$; for animal (B), the last detected time point was $24 \mathrm{~h}$. The mean of three animals is shown out to $48 \mathrm{~h}$ for which there were multiple time points to be averaged. For individual or average data, the plots from different assay formats demonstrate general agreement.

charge states $45+$ to $42+$ are shown for the intact $\mathrm{mAb}$, and the G0F/G0F and G0F/G1F glycan peaks can be observed for the initial time point $(15 \mathrm{~min})$ and $168 \mathrm{~h}$ post dose samples. The G0F glycan mass adduct is $1445 \mathrm{Da}$, and G1F an additional $162 \mathrm{Da}$. G0F or G1F are present on the Fc regions of the GSKmAb. In Supplementary Figure $1 \mathrm{~B}$, the $15 \mathrm{~min}$ and $168 \mathrm{~h}$ time point results are shown for the deconvoluted mass spectra which show similar abundances for the glycoforms at the two time points. At $168 \mathrm{~h}$, signal for GSKmAb was less abundant, thus affecting the overall spectral quality. As such, the G0F/G1F glycoform could not be distinguished with baseline resolution for this time point. To check relative glycoform detection, high $(40 \mu \mathrm{g} / \mathrm{ml})$ and low $(15 \mu \mathrm{g} / \mathrm{ml}) \mathrm{QC}$ samples are also shown in Supplementary Figure 1C, where similar glycoform abundances can be seen between the high versus low concentrations.

\section{Alternative sample analysis \& data processing strategies}

Deglycosylation of $\mathrm{mAb}$ therapeutics for intact mass analysis from in-life samples can provide a simplified, more homogeneous mass spectrum and perhaps enhanced sensitivity [15]. In this work, testing was performed using EndoS2 in the assay buffer to remove glycosylation (leaving a core GlcNAc at each glycosylation site) during the immunocapture step. Use of EndoS2 in the assay buffer achieved $\mathrm{mAb}$ capture and $\mathrm{mAb}$ deglycosylation in the same processing step, thus saving the processing time of an additional deglycosylation step. Supplementary Figure $2 \mathrm{~A}$ shows example data for samples spiked into serum at 5 and $50 \mu \mathrm{g} / \mathrm{ml}$, indicating successful removal of the N-glycans. Supplementary Figure 2B shows an example standard curve from method testing utilizing the deglycosylation step.

One major difference in HRMS versus QQQMS/MS data acquisition is the use of full scan $m / z$ ranges for HRMS compared with selected reaction monitoring for QQQ MS/MS. Use of QQQ MS or limited data acquisition in HRMS may be useful for cases where information on additional masses or mass variants is specifically not desired [11]. However, HRMS has the added benefit of catabolite discovery or relative mass variant quantitation [16]. The use 
of full scan range acquisition results in MS data containing multiple charge states. While deconvolution settings typically make use of the entire detected charge state distribution, absolute quantitation by XICs of selected charge states can utilize as many or as few charge states as desired to achieve absolute quantitation. Published examples have examined the use of multiple charge states and deconvolution [25,26]. For data presented in this study, 20 charge states were utilized; however, use of differing numbers of charge states or deconvolution was also examined for an interday run. Supplementary Table 2 shows the variability for QC sample results from a single day where 1, 3, 6 or all charge states were utilized. Supplementary Table 2 also shows results from MS intensity derived from deconvoluted intact mass. The samples and conditions that may be most impacted by use of differing charge states/deconvolution settings are the LLOQ and use of only a single charge state. All other samples and parameters produced similar variability $(\% \mathrm{CV})$. Statistical considerations aside, there exist inherent advantages and disadvantages for charge state summation as a mode of absolute quantitation. Advantages include that charge state summation is utilized from the raw data, and signal from shifting charge state distributions is accounted for. However, charge state summation requires most all charge state peaks to have sufficient signal-to-noise ratio for accurate quantitation near the LLOQ, and interfering protein peaks may be problematic if present.

Another sample processing parameter that may impact variability or assay results is the mass spectrum extraction width for each charge state [27]. In theory, if the charge state XIC extraction width is too narrow, signal may not be included for integration or the center of the $\mathrm{m} / \mathrm{z}$ peak may not be exact. If the charge state XIC extraction width is too wide, unnecessary noise may be incorporated. For absolute quantitation for the mock method validation and sample analysis, a charge state extraction width of $2 \mathrm{Da}$ was used which ensured the $m / z$ of the charge state peak was reproducibly captured. Data in Supplementary Table 3 demonstrate that variability is not impacted by the use of a narrower charge state extraction window.

\section{Discussion}

Assay design

Comparisons between different assay formats (such as LC-MS and LBA) can be useful for assay troubleshooting or evaluating new assay platforms. For in-life studies, differences such as target concentration (e.g., free vs total assay format), capture strategy (e.g., neutralizing, non-neutralizing or none), or circulating antidrug antibodies can impact sample concentration results and/or interpretation of results from different assays. For LBAs, sample dilution ratios or minimum-required dilutions can greatly impact assay readout due to concentration-dependent kinetic effects [3]. For this work, the surrogate peptide LC-MS/MS assay was designed to match a similar assay range and sample dilution scheme as the LBA. When the intact LC-MS assay was designed, the same considerations were made compared with the previous two assays. It is important to note that the lower LOD for each assay were not established. Rather, the assays were each optimized for the best performance at the expected unknown sample concentration ranges. Sample concentration agreement for LBA, peptide LC-MS and protein LC-MS assays indicate that the intact mass stability, total $\mathrm{mAb}$ and free $\mathrm{mAb}$ are comparable. Principal advantages of intact protein LC-MS are the detection of the intact mass species, faster sample preparation and less reagent cost. Other bioanalytical assay formats for large proteins only infer presence of the intact molecule, through either protein binding or surrogate peptide detection. Sample preparation for intact protein LC-MS assays can be as short as a few hours and use no enzyme for digestion, each of which is not the case for bioanalytical assays involving tryptic digestion. Disadvantages of intact protein LC-MS may include the requirement to use immunocapture, unfavorable assay sensitivity and slower data turnaround time (largely due to complex data sets) compared with established assay formats. Like LBAs, an antibody is required to bind the biotherapeutic analyte for intact protein LC-MS, and mass detection of the protein is limited to protein forms that the reagent antibody can capture. LBAs and peptide LC-MS assays can reach as low as $\mathrm{pg} / \mathrm{ml}$, whereas the intact protein LC-MS assays at the most sensitive are low $\mathrm{ng} / \mathrm{ml}$. The complex data arising from large protein LC-MS also requires specialized training for protein LC-MS data and associated software systems to properly analyze or process data, which is often not the case for data from LBAs or peptide LC-MS/MS assays. In this study, general agreement of the intact mass LC-MS assay to the LBA and surrogate peptide LC-MS/MS assays demonstrate stability of GSKmAb intact mass over time detected post dose, similar to data described previously for antibody subunits [28].

One major limitation for intact protein LC-MS is lack of differentiation of small or zero mass changes (e.g., Asn deamidation \& Asp isomerization) that can only be detected at the peptide level and can greatly impact higher-order structure and target binding [19,29]. If a molecule is known/thought to have such liabilities, additional digestionbased LC-MS/MS investigations may be needed to determine the levels of modifications at specific amino acid 
sites. If this is the case, complementary analyses via intact mass and peptide modification monitoring (e.g., beyond quantitation of a single, stable, unmodified surrogate peptide) is a better scientific design to assess a biotherapeutic based on mass. Thus, for general protein characterization, the advantages of intact protein MS (whole molecule monitoring \& primary sequence confirmation) and surrogate peptide MS/MS (mass variant localization to specific sites with $2-3$ orders of magnitude dynamic range) can be realized for in-life samples [30,31].

\section{Assay parameters related to performance \& the BMV}

The example data in Figures $3 \& 4$ give some indication of relative S/N at the assay LOQ $(5 \mu \mathrm{g} / \mathrm{ml})$ for single charge state XIC and summed mass spectra, where chromatographic $\mathrm{S} / \mathrm{N}$ is about 5 and spectral $\mathrm{S} / \mathrm{N}$ is about 3. Assay acceptance criteria of $20 / 25 \%$ were chosen based on established parameters for LBAs and hybrid LCMS/MS assays [23]. The intact protein LC-MS assay designed here has a few aspects aligned closely with LBAs. First, the immunocapture step is pivotal to assay performance (and required for mAb intact LC-MS work to date). Also, no internal standard is used, there is no digestion step and detection is based on the purified form of the circulating molecule. While some assays have incorporated internal standard for intact protein MS work, the use of an immunoassay plate for solid phase capture antibody coupling (which can accommodate $1-2 \mu \mathrm{g}$ of coating antibody) prohibits internal standard use in the capture step as it would further limit dynamic range. Use of internal standard in post capture processing may not provide a fundamental advantage to the assay, although it might be advantageous if samples were subject to variability during autosampler injection or ionization (this was not the case in this study).

In general, results from the precision and accuracy runs indicate favorable assay performance similar to LBAs. Some bias is present at the HLOQ $(-13.7 \%$ over 18 QCs), indicating that a different assay range might have been optimal, or a different curve fitting may have been appropriate. LBAs often employ four- or five-parameter logistic curve fits, but LC-MS assays traditionally utilize linear fits [32,33]. For the intact protein LC-MS assay, bias was still within assay acceptance parameters, and likely would not impact sample concentration results. Stability results are also an important consideration for the assay, and some of the stability results presented here have not been widely examined in prior studies (unlike assay precision and accuracy). Poor performance for intact mass stability under routine sample storage/handling conditions would be problematic for routine implementation for the assay. In this particular case, intact protein LC-MS was viable for long-term study support. The carry-over after a sample injection at the HLOQ is shown in Figure 4. Carry-over was determined to be less than about 3\%, but baseline noise levels in the blank sample prevent determination of carry over if present below 3\% (e.g., carry over is below limit of detection). A more-sensitive LC-MS assay would, in theory, permit a more sensitive assessment of carry-over. Use of TFA and molecule-specific properties may help limit carry-over, which should be evaluated on a case-by-case basis.

\section{Sample analysis, PK parameter \& data processing considerations}

As noted, design of the formats of the various assays is key to data comparison and interpretation. For the three assays discussed, the immunocapture step (and sample dilutions which can impact immunocapture) is pivotal to allow comparison between the assays. In each assay, it is important to consider that the drug forms that will be detected are only those which bind the capture reagent. AUC values were derived from all time points; based on the similarities for plots in Figure 5, the AUC last was determined to be similar between assay formats. Since Animal C demonstrated drug detection for the longest time post dose, the calculated AUC was higher. Future exposure assessments between assay formats from other researchers may provide a better evaluation of AUC for molecules with improved PK performance. In the future, expanding the assay sensitivity and dynamic range with an alternative immunocapture LC-MS platform may be useful to demonstrate a wider application for studies with lower dosing or longer duration.

An example of mass variant monitoring is shown in Supplementary Figure 1. Confirming that the glycosylation profile does not change over time may be useful, particularly in instances monitoring biotherapeutics with high mannose or high sialic acid content. It is important to consider the observed relative abundance with respect to sample concentration. If multiple reference standards consisting of different mass variants are available, QC mixing at different ratios can assist in determining the optimal assay range or in-life sample concentrations over which relative quantitation can be determined for the multiple IgG variants [34]. No other abundant mass variants were observed for the GSKmAb, likely due to the class of molecule (generic $\operatorname{IgG}$ ) and the relatively short time over which the drug could be detected from study samples. For the quantitative intact protein LC-MS assay used in mock 
method validation and sample analysis, deglycosylation could have been used for the LC-MS assay, since the data from Supplementary Figure 2 were comparable with the data in Figure 3.

If $\mathrm{N}$-glycosylation monitoring is not critical for the molecule, a deglycosylation step prior to intact $\mathrm{mAb}$ analysis from in-life samples can be utilized. Advantages and disadvantages exist to incorporating a deglycosylation step into the bioanalytical method [17]. Foremost, if there is high heterogeneity in N-linked glycosylation, deglycosylation can improve assay $\mathrm{S} / \mathrm{N}$ by reducing heterogeneity to a single intact mass, assuming no other abundant, modified forms are present. For ADCs or similar molecules with other types of heterogeneity, deglycosylation may simplify relative quantitation of other mass variants. Disadvantages include an additional step in sample processing, increased assay cost and the chance for an incomplete reaction or variability in reaction (if not optimized properly). In this study, deglycosylation was tested during method development/assessment. In order to limit additional sample processing steps, the enzyme EndoS2 was added to the serum/assay buffer mixture. Enzyme was added such that all IgG in the serum would be deglycosylated during the immunocapture step. Such a strategy removes the need for additional sample processing, but increases the amount and cost of enzyme required, and may not be feasible if larger serum/plasma volumes are needed for study support. From the data in Figure $3 \&$ Supplementary Figure 2, the spectral quality and reference standard curve linearity were comparable with or without deglycosylation, largely due to the overall relative abundance of the G0F/G0F glycoform. Thus, to eliminate the need for an additional sample processing step, deglycosylation was not utilized for the final method.

Varying data processing parameters for intact protein or full scan HRMS data may impact overall performance or variability of the assay. During method development, data processing parameters were tested along with assay parameters such as sample volume, incubation time and LC-MS conditions. To evaluate variables in data processing, different parameters were evaluated to determine which parameters could impact the quantitative results and may be pivotal for assay performance. In Supplementary Tables $2 \& 3$, data with variable charge states (fixed $2 \mathrm{~m} / \mathrm{z}$ extraction window) and variable mass extraction width (20 charge states used) are demonstrated. From this study, the results indicated that a number of parameters could be acceptable for data processing, but that these parameters should be optimized during method development. It should also be noted that the use of a $2 \mathrm{Da} m / z$ extraction window for 20 charge states was fixed for the mock validation runs and sample analysis. During the course of any method validation or sample analysis, changing the parameters for data processing may lead to inconsistencies in sample results (especially over the long term) or incurred sample reproducibility analysis. If it is determined that data processing changes are required, documentation of justification and/or cross-validation experiments may need to accompany the study package and a careful review may be required.

\section{Conclusion}

An immunocapture, intact protein LC-MS assay has been developed and tested by mock BMV experiments such as precision, accuracy and stability. The assay was used for analysis of serum samples from cynomolgus monkeys dosed GSKmAb. The results indicate that intact protein LC-MS assay performance was comparable to established assay formats, as LBA, surrogate peptide LC-MS/MS and intact protein LC-MS assay formats generated similar results from study samples. Intact protein LC-MS methods for PK study support are still in the early stages; however, as HRMS and immunocapture LC-MS application increases, increased adoption of intact protein LC-MS will follow.

\section{Future direction}

For discovery or molecule screening studies, intact protein LC-MS may replace peptide-based workflows due to simplicity and reduced enzyme cost. For regulated bioanalysis, intact protein LC-MS methods may need further optimization for sensitivity or robustness. With increasing complexity of biotherapeutics (e.g., ADCs, bispecific antibodies, fusion proteins and other mAb-based protein constructs) in drug discovery and development stages, intact protein LC-MS is predicted to see increased utility for absolute drug quantitation or relative quantitation of biotherapeutic mass variants. 
Executive summary

- For a human IgG mAb, an intact protein LC-MS assay is subjected to a mock bioanalytical method validation, and unknown samples are compared between intact protein LC-MS and established bioanalytical assay formats.

Results

- Precision and accuracy runs $(n=3)$, processed sample stability $(36 \mathrm{~h})$, room temperature stability $(24 \mathrm{~h})$, long-term storage stability (408 days), freeze-thaw stability $\left(5\right.$ cycles from $-80^{\circ} \mathrm{C}$ ) are presented.

- Results are presented from the traditional bioanalytical method evaluations along with demonstration of modification monitoring and evaluation of data processing parameters.

Discussion

- Areas for further improvement include streamlined data processing and software integrated with laboratory information management systems.

Conclusion/future direction

- With further data examples and assay optimizations, intact protein LC-MS methods can eventually be applied to regulated in-life sample analysis.

Financial \& competing interests disclosure

The research was supported by GlaxoSmithKline Research and Development and Waters Corp. The authors are employees of their respective institutions and may be eligible for stock options or have stock ownership. The authors have no other relevant affiliations or financial involvement with any organization or entity with a financial interest in or financial conflict with the subject matter or materials discussed in the manuscript apart from those disclosed.

No writing assistance was utilized in the production of this manuscript.

\section{Open access}

This work is licensed under the Attribution-NonCommercial-NoDerivatives 4.0 Unported License. To view a copy of this license, visit http://creativecommons.org/licenses/by-nc-nd/4.0/

\section{References}

Papers of special note have been highlighted as: $\bullet$ of interest; $\bullet \bullet$ of considerable interest

1. Lee JW, Kelley M, King LE et al. Bioanalytical approaches to quantify "total" and "free" therapeutic antibodies and their targets: technical challenges and PK/PD applications over the course of drug development. AAPS J. 13(1), 99-110 (2011).

2. Khan MN, Findlay JW (Eds). Ligand-Binding Assays: Development, Validation, and Implementation in the Drug Development Arena. John Wiley \& Sons, NJ, USA (2009).

3. DeSilva B, Smith W, Weiner R et al. Recommendations for the bioanalytical method validation of ligand-binding assays to support pharmacokinetic assessments of macromolecules. Pharm. Res. 20(11), 1885-1900 (2003).

4. Chang H-P, Shah DK. Determination of ADC concentration by ligand-binding assays. In: Tumey LN (Ed.). Antibody-Drug Conjugates: Methods and Protocols. Springer US, NY, USA 361-369 (2020).

5. Jiang $\mathrm{H}$, Zeng J, Titsch C et al. Fully validated LC-MS/MS assay for the simultaneous quantitation of coadministered therapeutic antibodies in cynomolgus monkey serum. Anal. Chem. 85(20), 9859-9867 (2013).

6. Russo R, Rega C, Caporale A et al. Ultra-performance liquid chromatography/multiple reaction monitoring mass spectrometry quantification of trastuzumab in human serum by selective monitoring of a specific peptide marker from the antibody complementarity-determining regions. Rapid Com. Mass Spectrom. 31(14), 1184-1192 (2017).

7. Xu X, Huang Y, Pan $\mathrm{H}$ et al. Quantitation and modeling of post-translational modifications in a therapeutic monoclonal antibody from single- and multiple-dose monkey pharmacokinetic studies using mass spectrometry. PLoS ONE 14, e0223899 (2019).

8. Duggan JX, Vazvaei F, Jenkins R. Bioanalytical method validation considerations for LC-MS/MS assays of therapeutic proteins. Bioanalysis 7(11), 1389-1395 (2015).

9. Fu Q, Chen Z, Zhang $S$ et al. Multiple and selective reaction monitoring using triple quadrupole mass spectrometer: preclinical large cohort analysis. In: Sechi S (Ed.). Quantitative Proteomics by Mass Spectrometry. Springer New York, NY, USA 249-264 (2016).

10. Maráková K, Rai AJ, Schug KA. Effect of difluoroacetic acid and biological matrices on the development of a liquid chromatography-triple quadrupole mass spectrometry method for determination of intact growth factor proteins. J. Sep. Sci. 43(9-10), 1663-1677 (2020).

11. Wang EH, Combe PC, Schug KA. Multiple reaction monitoring for direct quantitation of intact proteins using a triple quadrupole mass spectrometer. J. Am. Soc. Mass Spectrom. 27, 886-896 (2016). 
12. Ramagiri S, Garofolo F. Large molecule bioanalysis using Q-TOF without predigestion and its data processing challenges. Bioanalysis 4(5), 529-540 (2012).

13. Cox JM, Berna MJ, Jin Z et al. Characterization and quantification of oxyntomodulin in human and rat plasma using high-resolution accurate mass LC-MS. Bioanalysis 8(15), 1579-1595 (2016).

14. Li F, Weng Y, Zhang G, Han X, Li D, Neubert H. Characterization and quantification of an fc-FGF21 fusion protein in rat serum using immunoaffinity LC-MS. AAPS J. 21(5), 84 (2019).

-• Demonstrates some aspects of a bioanalytical method validation for an intact protein.

15. Lanshoeft C, Cianférani S, Heudi O. Generic hybrid ligand binding assay liquid chromatography high-resolution mass spectrometry-based workflow for multiplexed human immunoglobulin G1 quantification at the intact protein level: application to preclinical pharmacokinetic studies. Anal. Chem. 89(4), 2628-2635 (2017).

- Seminal article for intact $\mathrm{mAb}$ MS for pharmacokinetic determination.

16. Kang L, Camacho RC, Li W et al. Simultaneous catabolite identification and quantitation of large therapeutic protein at the intact level by immunoaffinity capture liquid chromatography-high-resolution mass spectrometry. Anal. Chem. 89(11), 6065-6075 (2017).

- Seminal article for intact protein MS for pharmacokinetic determination.

17. Vasicek LA, Zhu X, Spellman DS, Bateman KP. Direct quantitation of therapeutic antibodies for pharmacokinetic studies using immuno-purification and intact mass analysis. Bioanalysis 11(3), 203-213 (2019).

-• Demonstrates extensive analysis of intact $\mathrm{mAbs}$ from pre clinical samples and shows method performance and data analysis considerations.

18. Hall MP. Biotransformation and in vivo stability of protein biotherapeutics: impact on candidate selection and pharmacokinetic profiling. Drug Met. Dispos. 42(11), 1873-1880 (2014).

19. Kellie JF, Karlinsey MZ. Review of approaches and examples for monitoring biotransformation in protein and peptide therapeutics by MS. Bioanalysis 10(22), 1877-1890 (2018).

20. Shah VP, Midha KK, Findlay JW et al. Bioanalytical method validation - a revisit with a decade of progress. Pharm. Res. 17(12), 1551-1557 (2000).

21. Shah VP. The history of bioanalytical method validation and regulation: evolution of a guidance document on bioanalytical methods validation. AAPS J. 9(1), E43-E47 (2007).

22. Kaur S, Bateman KP, Glick J et al. IQ consortium perspective: complementary LBA and LC-MS in protein therapeutics bioanalysis and biotransformation assessment. Bioanalysis 12(4), 257-270 (2020).

23. Jenkins R, Duggan JX, Aubry A-F, Zeng J, Lee JW, Cojocaru L et al. Recommendations for validation of LC-MS/MS bioanalytical methods for protein biotherapeutics. AAPS J. 17(1), 1-16 (2015).

24. Hughes NC, Wong EY, Fan J, Bajaj N. Determination of carryover and contamination for mass spectrometry-based chromatographic assays. AAPS J. 9(3), E353-E360 (2007).

25. Kellie JF, Kehler JR, Karlinsey MZ, Summerfield SG. Toward best practices in data processing and analysis for intact biotherapeutics by MS in quantitative bioanalysis. Bioanalysis 9(23), 1883-1893 (2017).

- Details data processing considerations for MS of intact antibody subunits and small biotherapeutics.

26. Qiu X, Kang L, Case M, Weng N, Jian W. Quantitation of intact monoclonal antibody in biological samples: comparison of different data processing strategies. Bioanalysis 10(13), 1055-1067 (2018).

- Details data processing considerations for MS of intact monoclonal antibodies.

27. Gt Glauser, Grund B, Gassner A-L et al. Validation of the mass-extraction-window for quantitative methods using liquid chromatography high resolution mass spectrometry. Anal. Chem. 88(6), 3264-3271 (2016).

28. Kellie JF, Pannullo KE, Li YB et al. Antibody subunit LC-MS analysis for pharmacokinetic and biotransformation determination from in-life studies for complex biotherapeutics. Anal. Chem. 92(12), 8268-8277 (2020).

29. Schuster J, Koulov A, Mahler H-C et al. In vivo stability of therapeutic proteins. Pharm. Res. 37(2), 1-16 (2020).

30. Doell A, Schmitz OJ, Hollmann M. Shedding light into the subcutis: a mass spectrometry based immunocapture assay enabling full characterization of therapeutic antibodies after injection in vivo. Anal. Chem. 91(15), 9490-9499 (2019).

31. Kellie JF, Thomson AS, Chen S et al. Biotherapeutic antibody subunit LC-MS and peptide mapping LC-MS measurements to study possible biotransformation and critical quality attributes in vivo. J. Pharm. Sci. 108(4), 1415-1422 (2019).

32. Findlay JW, Dillard RF. Appropriate calibration curve fitting in ligand binding assays. AAPS J. 9(2), E260-E267 (2007).

33. Sleczka BG, Mehl JT, Shuster DJ et al. Quantification of human mAbs in mouse tissues using generic affinity enrichment procedures and LC-MS detection. Bioanalysis 6(13), 1795-1811 (2014).

34. Li W, Srikumar N, Forrest WF et al. Characterizing and quantitating therapeutic tethered multimeric antibody degradation using affinity capture mass spectrometry. Anal. Chem. 92(10), 6839-6843 (2020). 
